\title{
ANÁLISIS DE LA DIÁSPORA COLOMBIANA EN MÉXICO: HISTORIA, ESTADÍSTICAS Y LECTURAS DE CAUSALIDADES*
}

\author{
Analysis of the Colombian \\ Diaspora in MEXICO: History, \\ Statistics and Causalities Review
}

\author{
ANÁlise DA DIÁSPORA \\ COlOMBiana No MÉxico: \\ HISTÓRIA, ESTATÍSTICAS E \\ LEITURAS DE CAUSALIDADES
}

\author{
SEBASTIÁN POLO ALVIS** \\ ENRIQUE SERRANO-LÓPEZ*** \\ CAROLINA BERNAL-MÁRQUUEZ****
}

\footnotetext{
* La presente investigación se realizó en el marco del Semillero de Migraciones Colombianas al Exterior (Semicoex) de la Universidad del Rosario. Los autores agradecen a Francelly Triana y a Ángela Mora por su colaboración para la realización de este artículo.

** orcid.org/0000-0003-2950-6710. Universidad del Rosario, Colombia. sebastian.polo@urosario.edu.co

*** $\quad$ orcid.org/0000-0001-9340-3236. Universidad del Rosario, Colombia. enrique.serrano@urosario.edu.co

**** orcid.org/0000-0002-4721-2735. Universidad del Rosario, Colombia. carolina.bernalma@urosario.edu.co
}

RECIBIDO: 24 DE FEBRERO DE 2018. ENVÍO A PARES: O1 DE MARZO DE 2018 APROBADO POR PARES: 23 DE NOVIEMBRE DE 2018. ACEPTADO: 25 DE NOVIEMBRE DE 2018

DOI: $10.5294 / D I K A .2019 .28 .1 .4$ 


\section{RESUMEN}

Este trabajo se enfoca en analizar la naturaleza de la migración colombiana hacia México durante los últimos 30 años. Mediante la exposición de cifras y evoluciones estadísticas se pretende construir un análisis cualitativo y argumentativo de la situación migratoria de los colombianos en México. Metodológicamente, la revisión de líneas de progresión estadísticas en cifras absolutas de población residente, de flujos migratorios de salida, y de otros elementos estadísticos pertinentes como método de identificación de tendencias migratorias, al igual que la revisión de la historia migratoria de México para la identificación del inicio y evolución de la migración colombiana en este país, buscan ser elementos que permitan al lector aproximarse y reflexionar sobre las diversas dimensiones del fenómeno en cuestión.

\section{PALABRAS CLAVE}

Migraciones; migración laboral; diáspora; México; América Latina; población. 


\section{ABSTRACT*}

This paper focuses on analyzing the nature of Colombian migration to Mexico in the last 30 years. In presenting figures and statistical evolutions, we intend to carry out a qualitative and argumentative analysis of the migratory situation of Colombians in Mexico. Methodologically, we reviewed lines of statistical progression in absolute numbers of resident population, migratory outflows and other relevant statistical elements to identify migratory trends and explored the migratory history of Mexico to determine the beginning and evolution of Colombian migration in this country. These elements will allow the reader to approach to and reflect on the various dimensions of the phenomenon concerned.

\section{KEYWORDS}

Migrations; labour migration; diaspora; Colombia; México; Latin America; population. 


\section{RESUMO*}

Este trabalho se enfoca em analisar a natureza da migração colombiana para o México nos últimos 30 anos. Por meio da exposição de cifras e evoluções estatísticas, pretende-se construir uma análise qualitativa e argumentativa da situação migratória dos colombianos no México. Metodologicamente, a revisão de linhas de progressão estatística em cifras absolutas de população residente, de fluxos migratórios de saída e de outros elementos estatísticos pertinentes como método de identificação de tendências migratórias, bem como a revisão da história migratória do México para a identificação do início e da evolução da imigração colombiana nesse país, buscam ser elementos que permitam ao leitor aproximar-se e refletir sobre as diversas dimensões do fenômeno em questão.

\section{PALAVRAS-CHAVE}

Migrações; migração laboral; diáspora; México; América Latina; população.

* A presente pesquisa foi realizada no âmbito do grupo Semillero de Migraciones Colombianas al 
SUMARIO: INTRODUCCIÓN. 1. UN HORIZONTE DE TARdía AURORA: LA APERTURA DE MÉXICO COMO DESTINO MIGRATORIO. 2. MÉXICO: UN NUEVO PUERTO PARA LA DIÁSPORA COLOMBIANA.

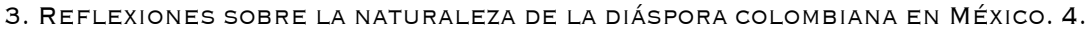
CONCLUSIONES. BiBLIOgRAFía.

\section{INTRODUCCIÓN}

Desde el siglo XIX, México ha experimentado procesos políticos de gran turbulencia que han marcado diversas lógicas políticas, económicas y sociales en el país. Los diversos escenarios de contraposición política entre formas de gobierno monárquicas y republicanas, al igual que los escenarios de disputa politica sobre la autonomía de los entes territoriales, la supremacía de algunas regiones del país, la intervención política y militar de potencias como Estados Unidos, Francia, Reino Unido, entre otros, fueron determinantes para definir la percepción del pueblo mexicano frente al mundo, específicamente en América Latina. ${ }^{1}$ Sin embargo, a pesar de esta multiplicidad de elementos formadores, existe un factor que sería determinante para la construcción social del país, específicamente a lo largo del siglo XX: los procesos migratorios.

El objetivo principal del presente texto se enfoca en analizar la naturaleza de la migración colombiana durante los últimos 30 años. Más allá de la exposición de cifras y evoluciones estadísticas, es un análisis cualitativo y argumentativo de la situación migratoria de los colombianos en México. En primer lugar, se busca hacer una lectura preliminar a través de la revisión de líneas de progresión estadísticas en cifras absolutas de población residente, de flujos migratorios de salida, y de otros elementos estadísticos pertinentes como método de identificación de tendencias migratorias.

En segundo lugar, se hará una revisión constructivista de la historia migratoria de México para la identificación del inicio y la evolución de la migración colombiana en este país, y la tipificación de particularidades que sean inherentes a los procesos migratorios de los colombianos en este país, como elementos metodológicos que serán de vital importancia para el curso natural del presente trabajo. Se mantiene como expectativa que el lector pueda familiarizarse con la naturaleza de la migración colombiana en México, dentro de una multiplicidad de procesos sociales de los migrantes en este país.

\section{UN HORIZONTE DE TARDÍA AURORA: LA APERTURA DE MÉXICO COMO DESTINO MIGRATORIO}

Dentro de la historia de México, las migraciones han sido uno de los procesos de importancia transversal en la construcción económica, política y social del país. Además de su historia de emigración caracterizada por la diáspora mexicana hacia

1 Thomas Lothar Weis y Pedro López Chaltel, México: politicas públicas beneficiando a los inmigrantes, Ciudad de México, Editorial OIM, 2011. 
Estados Unidos, México experimentó procesos de recepción de migrantes a lo largo del periodo posterior a la independencia, al punto de concebir que "el México poscolonial no puede entenderse como nación sin entender a los inmigrantes". ${ }^{2}$ De acuerdo con Rebolledo Kloques, la historia migratoria mexicana se puede dividir en dos secciones que describen la naturaleza de las iniciativas politicas para la atracción de migrantes: "la primera, caracterizada por el interés manifiesto y urgente de atraer inmigrantes; la segunda, marcada por limitar su entrada y reducir su presencia de la vida nacional". ${ }^{3}$

La turbulencia de sus primeros años de historia tendría inicio en la inestabilidad politica derivada del fracaso en la instauración de las metas propuestas en el Plan de Iguala de 1824, que compondría el proyecto del Primer Imperio Mexicano, el cual buscaba la implementación de las tres garantías: la unidad de las naciones mexicana y española, la independencia y el respeto por la fe católica. ${ }^{4}$ Este proyecto político era contradictorio, lo cual derivó en diversos procesos políticos a nivel interno, como el desarrollo de proyectos republicanos.

Elementos como la escisión de las Provincias Unidas de Centro América en 1824, la instalación de la Primera República Mexicana de corte federal en el mismo año, entre otros, fueron acontecimientos que incidirian directamente en los contextos políticos y sociales de México y moldearian sus iniciativas migratorias. Por ejemplo, se percibieron procesos migratorios de considerable importancia a raíz de la Ley General de Colonización de 1824. Dicha ley permitió a los extranjeros "obtener títulos de propiedad, además de exentarlos de impuestos durante 4 años", ${ }^{5} \mathrm{y}$ localizó la colonización en regiones como los estados de Coahuila y Texas. Esta iniciativa provocó la migración masiva de estadounidenses, lo cual derivaría en una incidencia directa de esta migración en los sucesos posteriores que conducirian a la independencia de Texas en 1836, y la posterior guerra mexicano-estadounidense (1846-1848).

Esta pérdida territorial no solo impidió un desarrollo de la migración que redundara en un beneficio general para México, sino que se comenzaria a generar un sentimiento de suspicacia ante la presencia extranjera en México, al punto de que "terminó provocando un trauma severo en la psique colectiva que pudo haber marcado indeleblemente la percepción que más tarde tendría la presencia de los extranjeros en el país". ${ }^{6}$ No obstante, aunque la guerra derivó en una pérdida territorial sin precedentes, los flujos migratorios de europeos hacia México no

2 Pablo Yankelevich, Inmigración y racismo. Contribuciones a la historia de los extranjeros en México, México, El Colegio de México, 2015.

3 Octavio Rebolledo Klogues, "Extranjeros, nacionalismo y politica migratoria en el México independiente, 1821-2000”, Tesis doctoral. Repositorio Universidad de Granada, 2016, p. 162.

4 Jan Bazant, "México", en Leslie Bethell (ed.), Historia de América Latina. Tomo VI, América Latina Independiente, 1820-1870, Barcelona: Critica, 1991, p. 105.

5 David Weber, The Mexican frontier, 1821-1846: the American Southwest under Mexico. Santa Fe: University of New Mexico Press, 1982, p. 162.

6 Octavio Rebolledo Klogues, "Extranjeros, nacionalismo y política migratoria en el México independiente, 1821-2000”, op. cit., p. 244. 
cesaron, puesto que a mediados de la década de los cincuenta del siglo XIX llegaron "sastres, mercaderes, zapateros y boticarios de Francia, comerciantes de Alemania, hombres de negocios de la Gran Bretaña”. ${ }^{7}$

Desde la independencia de México las migraciones no fueron un elemento de influencia constitutiva, como lo fue en los casos de Brasil, Argentina y Chile, pues se vio afectado transversalmente por una constante presencia de procesos de secesión, guerras civiles e intervenciones exteriores que redujeron el atractivo de México como un destino de migración masiva.

La consolidación de un Estado moderno, tras la segunda intervención francesa en México entre 1861 y 1867, llevó al fortalecimiento de un proyecto liberal que incentivaría que, "con la eliminación del catolicismo como religión oficial, con la disminución del papel político de la Iglesia y con la destrucción de la base económica de su poder político, México, como los Estados Unidos, atrajera a inmigrantes europeos de todas las religiones", los cuales contribuirian a "una clase media agrícola que aseguraría el rápido crecimiento económico, la estabilidad política y el desarrollo de las instituciones democráticas", ${ }^{8}$ estableciendo una red moderna de propiedades de menor tamaño, en detrimento de los intereses de posesión de tierras por parte de la Iglesia y de las poblaciones indígenas. Sin embargo, a pesar de los esfuerzos por consolidar la migración como alternativa de repoblamiento del territorio tras medio siglo de guerras civiles y exteriores,

La inmigración continuó siendo mínima y preferentemente de comerciantes, empresarios y técnicos de clase media y alta. Los salarios en la industria eran demasiado bajos para atraer trabajadores europeos [...] y los trabajadores agrícolas europeos no aceptaban los bajos sueldos ofrecidos por los hacendados mexicanos y mientras hubiera posibilidad de emigrar a los Estados Unidos, no veían ninguna razón para cruzar la frontera hacia el sur. ${ }^{9}$

Sin embargo, a finales del siglo XIX se lograría la pacificación de la frontera norte como resultado de la derrota de los apaches y el desarrollo del ferrocarril, lo cual incentivó un aumento poblacional en los estados de Sonora, Chihuahua, Durango y Nuevo León, manifestado en el arribo de “15.000 estadounidenses y 300.000 mexicanos desempleados a esta zona entre 1877 y 1910, atraídos por la proliferación de actividades económicas relacionadas con la minería", ${ }^{10}$ el cual dio inicio al desarrollo de una interacción interfronteriza entre mexicanos y las zonas del sur de Estados Unidos que sería determinante para la consolidación de la migración masiva de mexicanos hacia Estados Unidos.

Daniel Cosío Villegas et al., Historia mínima de México, Ciudad de México, El Colegio de México, 1974, p. 69.

8 Friedrich Katz, "México: la restauración de la República y el Porfiriato, 1867-1910", en Leslie Bethell, (ed.), Historia de América Latina. Tomo IX, México, América Central y el Caribe, 1870-1930,

$9 \quad$ Ibid., p. 35.

$10 \quad$ Ibid., p. 47. 
Sin embargo, la difícil asimilación cultural de las poblaciones migrantes, al igual que la creciente presencia de estadounidenses en la región norte de México, generó tensiones politicas y sociales entre sectores obreros, estudiantiles y empresariales ante la imposibilidad de activar económicamente a la población joven mexicana, además de las razonables suspicacias de la migración estadounidense como un paso inicial para una nueva anexión territorial de Estados Unidos.

A pesar de los esfuerzos estatales realizados durante el Porfiriato (1877-1911), tales como la expedición de la Ley de Extranjería y Naturalización de 1886, y la Ley de Migración de 1909, la migración hacia México no logró ser masiva, aunque fue de un aporte sustancial para la industrialización de la economía mexicana. De acuerdo con el I Censo de la República Mexicana de 1895, a pesar de que se percibieron entradas de alemanes, franceses, españoles, sirios, chinos, estadounidenses, ingleses, en el país residian apenas 56.355 extranjeros provenientes principalmente de España, Guatemala y Estados Unidos, ${ }^{11}$ lo que denota un nivel bajo de presencia extranjera en comparación con cifras homólogas de Brasil, Argentina y Chile.

De acuerdo con Rebolledo Kloques, una de las posibles razones de los bajos resultados de la iniciativa migratoria de Porfirio Díaz reside en una cuestión de imposibilidad para los migrantes de lograr una movilidad social y de atractivo como destino para rehacer sus vidas, lo que provocó el redireccionamiento de las diversas migraciones hacia otros destinos:

La estrategia de colonización del país fue obra del grupo de "los científicos", quienes reflejaban el pensamiento de una oligarquía que había crecido al amparo del presidente Díaz. Aparte de la élite intelectual, esta agrupaba a hacendados, dueños de minas e inversionistas que requerian de mano de obra barata para sus empresas, es decir, peones y jornaleros dispuestos a trabajar disciplinados en las tareas, y suficientemente sumisos como para no distraer su atención con luchas reivindicativas ni demandas por un mejor salario. ${ }^{12}$

No obstante, a pesar del panorama anterior, el número de extranjeros para 1910 en el país ascendería a 117.108, cifra que doblaba en proporción los registros de $1895,{ }^{13}$ y mantenia la predominancia de españoles, guatemaltecos y estadounidenses, además de la presencia de otras poblaciones de considerable importancia como los sirio-libaneses, alemanes, franceses e italianos. Dicho crecimiento obedece a una estabilización política interna, un régimen económico autocrático y austero, el restablecimiento de relaciones diplomáticas con las diversas potencias, entre otros elementos que propiciaron un aumento de los flujos mencionados. ${ }^{14}$

11 Instituto Nacional de Estadística y Geografí (Inegi), Base de Datos de Censos de Población y Vivienda. Ciudad de México: Instituto Nacional de Estadística y Geografia, 2018.

12 Rebolledo Klogues, "Extranjeros, nacionalismo y política migratoria en el México independiente, 1821-2000”, op. cit., p. 227.

13 Inegi, Base de Datos de Censos de Población y Vivienda, op. cit.

14 Rebolledo Klogues, "Extranjeros, nacionalismo y política migratoria en el México independiente, 1821-2000”, op. cit., p. 137. 
Pero, a pesar de que entre 1900 y 1910 el flujo de la inversión extranjera en el país alcanzó proporciones sin precedentes, estimadas en 3000 millones de dólares, "esta nueva ola de inversiones desembocó en una brusca subida de los precios que posteriormente se vio acentuada por la decisión del Gobierno de abandonar el patrón plata y adoptar el patrón oro". ${ }^{15}$ La alta volatilidad de la economía, expresada en una aguda depresión económica que se conjugó con un periodo de malas cosechas y desempleo creciente, y el mal manejo político derivado de una total ausencia de renovación política a lo largo del Porfiriato, ${ }^{16}$ devinieron en una crisis económica y social entre 1907 y 1908 que desembocó en la Revolución mexicana de 1910.

Dicha situación condicionó un escenario inestable para las migraciones masivas en el país que, en el desarrollo de la guerra civil entre 1910 y 1920, reforzaría la tendencia emigratoria durante el mencionado periodo, en el que "la guerra, la emigración y la gripe habian reducido de 15 millones a unos 14,7 millones de personas". ${ }^{17}$ Tras la Revolución mexicana se promulga la Constitución Política de los Estados Unidos Mexicanos en 1917, la cual establece elementos sobre asuntos migratorios que fueron recogidos de la Constitución de 1857. Asimismo, en el gobierno de Plutarco Elías Calles (1924-1928) se da un giro en la política pública sobre migración con la expedición de la Ley de Migración de 1926, cuyo talante sería restrictivo y nacionalista:

\begin{abstract}
Se inicia una etapa histórica caracterizada por la instauración de inéditas bases ideológicas que fundamentarán el nacionalismo emanado de la revolución y, con él, el establecimiento de severas pautas de selección de los inmigrantes, preceptos que más tarde serán plasmadas en una legislación caracterizada por ser altamente restrictiva. Mediante la implementación de "Tablas Diferenciales", las cuales serian aplicadas a las solicitudes de inmigración de determinadas nacionalidades, se restringió la entrada de trabajadores de origen sirio, palestino, libanés, árabe, turco y armenio, agregándose más tarde a los indo-británicos, chinos y negros. ${ }^{18}$
\end{abstract}

No obstante, con el fortalecimiento de una economía de mercado a lo largo de la década de los veinte, la alta injerencia de capitales extranjeros en la estabilidad económica y política del país impulsó el avance de un proceso de mayor participación económica nacional en la economía, basado en el progresivo incremento de la explotación minera y del petróleo. Paradójicamente, a pesar de las restricciones migratorias en la legislación mexicana, la población extranjera en México tuvo un cénit en 1930, en la que se registraron 159.844 residentes. ${ }^{19}$

15 Katz, "México: la restauración de la República y el Porfiriato, 1867-1910", op. cit., p. 65.

16 Cosio Villegas, Historia mínima de México, op. cit.

17 John Woмack JR, "La Revolución Mexicana, 1910-1920", en Leslie Bethell (ed.), Historia de América Latina. Tomo IX, México, América Central y el Caribe, 1870-1930, Barcelona, Crítica, 1991, p. 145.

18 Rebolledo Klogues, "Extranjeros, nacionalismo y politica migratoria en el México independiente, 1821-2000”, op. cit., p. 180.

19 Inegi, Base de Datos de Censos de Población y Vivienda, op. cit. 
A raíz de lo anterior, el desarrollo de las migraciones en México tendría un nuevo aire con el auge económico experimentado entre 1936 y 1970 llamado el "Milagro mexicano", influido por la nacionalización del petróleo y de los ferrocarriles en 1938 durante el gobierno de Lázaro Cárdenas del Río (1936-1940), además del creciente flujo comercial entre México y Estados Unidos durante la Segunda Guerra Mundial. Este escenario económico incentivó el constante flujo de capitales y el fortalecimiento de la migración de mexicanos hacia Estados Unidos. ${ }^{20}$

Asimismo, los sucesivos conflictos internacionales fomentaron el arribo de españoles republicanos de la guerra Civil Española, al igual que la "migración de guatemaltecos, salvadoreños, nicaragüenses y hondureños en las regiones sur de México como Chiapas y Oaxaca”, ${ }^{21}$ y de la presencia de refugiados europeos de diversas nacionalidades que huyeron de la guerra. De acuerdo con las cifras del VI Censo Nacional de Población de 1950, se registran 106.115 extranjeros residentes en México, lo cual significa un descenso estadístico en comparación con los registros de $1930 .{ }^{22}$ A pesar de dicho decrecimiento, se realizaron avances jurídicos y políticos para la comprensión adecuada de los fenómenos migratorios con la Ley General de Población de 1936, en la que debía brindársele "facilidades a los extranjeros asimilables y cuya función sea más conveniente para las razas del país”. ${ }^{23}$

Empero, a pesar de la implementación del sistema de desarrollo estabilizador basado en un proceso de industrialización por sustitución de importaciones durante los años cincuenta y sesenta, cabe resaltar que durante la Guerra Fría, México se caracterizó por el manejo de una política internacional independiente, lo cual ayudó a que se convirtiera en un país de refugio y de exilio político para un número considerable de personas provenientes de diversas nacionalidades latinoamericanas. Esta iniciativa tendría asidero jurídico en las transformaciones estipuladas en la Ley General de Población de 1947, en la que tras la Segunda Guerra Mundial, se da una apertura migratoria en el país.

Además, como elemento innovador, en el artículo 42 de dicha ley se estipulan nuevas categorias de ingreso al país, tales como los asilados politicos, los refugiados y los transmigrantes; denominaciones que influirian en diversos procesos migratorios a nivel regional. Efecto de estas reformas migratorias, en conjugación con diversos elementos coyunturales, es el progresivo aumento del número de extranjeros residentes en territorio mexicano entre 1950 y 1980, el cual registra un incremento demográfico del $156 \%$ representado en un total de $268.900{ }^{24}$

20 Alan Knight, “México, 1930-1946”, en Leslie Bethell (ed.), Historia de América Latina. Tomo XIII, México y el Caribe desde 1930, Barcelona, Crítica, 1991.

21 Ibid., p. 70.

22 Inegi, Base de Datos de Censos de Población y Vivienda, op. cit.

23 Instituto Nacional de Migración (INM), Compilación histórica de la Legislación migratoria en México, 1821-2002, 3 ed. México D.F., Secretaría de Gobernación, 2003, p. 185.

24 Inegi, Base de Datos de Censos de Población y Vivienda op. cit. 
Esta fase de recepción de refugiados se puede dividir en dos periodos: el periodo temprano entre 1954 y 1963, caracterizado por el ingreso de guatemaltecos, cubanos, nicaragüenses, hondureños y dominicanos. ${ }^{25}$ La segunda fase, correspondiente al periodo de recepción de exiliados políticos latinoamericanos se daría entre 1964 y 1992, como resultado de la proliferación de dictaduras militares en América Latina, y de guerras civiles y conflictos armados marcados por la confrontación ideológica característica de la Guerra Fría, además de la influencia de Estados Unidos en torno a la implementación de la Doctrina de Seguridad Nacional contra el comunismo en la región, lo que causó que llegaran a México exiliados brasileños, peruanos, uruguayos, chilenos, argentinos, nicaragüenses, salvadoreños y colombianos. ${ }^{26}$ No obstante, a pesar de la expansión del número de extranjeros, tanto regulares como irregulares, la tendencia principal de las migraciones en el país fue marcada transversalmente por la diáspora mexicana hacia Estados Unidos, la cual cambiaría abruptamente con la aprobación del Simpson-Rodino Act por Ronald Reagan, como medida paliativa para la migración ilegal.

Además, tras el desproporcionado crecimiento de la deuda pública, el Milagro Mexicano terminaría en 1988 con:

... el presidente Carlos Salinas de Gortari, [quien] intensificó la reforma económica estructural iniciada en el sexenio de Miguel de la Madrid (1982-1988) con el fin de incrementar el nivel de desarrollo del país. Para ello, el gobierno privatizó innumerables empresas públicas y desreguló la economía, principalmente con respecto al mercado internacional. A pesar de la aparente solidez de una coalición política que había dado su apoyo a un modelo de desarrollo implantado desde los años 40 basados en la sustitución de importaciones y el control del estado sobre actividades estratégicas [...] Pocas semanas después de que Salinas dejara la presidencia sobrevino una nueva crisis financiera. El peso se devaluó más de $100 \%$, aunque luego se estabilizó por unos meses en alrededor del 70\% del tipo de cambio previo a la devaluación. ${ }^{27}$

A pesar de estas condiciones, con el refortalecimiento económico de México tras el abandono del sistema de industrialización por sustitución de importaciones este

25 Exiliados políticos por condiciones endémicas de persecución politica, dadas por sucesos que fueron de trascendencia mundial en temas de refugio como el golpe de Estado perpetrado a Jacobo Árbenz en Guatemala en 1954, y el conflicto armado interno en Guatemala desde 1960; el estallido de la Revolución Cubana en 1959; la persecución política prohijada durante el dominio de la dinastía Somoza en Nicaragua entre 1936 y 1979; el establecimiento de la dictadura de Oswaldo López Arellano en Honduras en 1963, y la fundación del Servicio de Inteligencia Militar a finales de los años cincuenta como órgano de control y persecución de Rafael Leónidas Trujillo en República Dominicana.

26 Exiliados políticos por condiciones endémicas de persecución política, dadas por sucesos que fueron de trascendencia mundial en temas de refugio como la instalación de la Junta Militar en Brasil en 1964, los golpes de Estado en Uruguay y Chile en 1973, el ascenso de la Junta Militar en Argentina en 1976, el estallido de la Revolución Sandinista de 1979 en Nicaragua y de la Guerra Civil de El Salvador en 1980, además del exilio político causado por la crisis de seguridad en Colombia y Perú durante los años ochenta y noventa.

27 Carlos Elizondo MaYer-SERra, "Tres trampas: sobre los orígenes de la crisis económica mexicana de 1994", en Revista de Economía Politica 18 (1997), pp. 122-123. 
país se desarrollaría como un centro atractivo de inversión y migración; avances reflejados en su ingreso al General Agreement on Tariffs and Trade (GATT) en 1986; en la firma del Tratado de Libre Comercio con América del Norte en 1992, y en el ingreso de México a la Organización para el Comercio y el Desarrollo Económicos (OCDE) en el mismo año, lo cual demostró "un serio compromiso del Estado en el proceso de liberalización de la economía”, ${ }^{28}$ además de que daba visos de una mejoría constante que mantendría un atractivo económico para la migración hacia este país.

Estas condiciones, además de otros elementos coyunturales como las grandes migraciones de salvadoreños, guatemaltecos y hondureños que fueron transmigrantes en México para llegar a Estados Unidos, configuraron un nuevo escenario migratorio para este país que se mantendría vigente por los próximos 25 años. Actualmente, el compendio legal sobre asuntos migratorios en México se puede reunir en la Ley de Migración de 2011, complementaria en sus competencias a la Ley General de Población de 1990, en la que se expresa como objetivo principal "regular los fenómenos que afectan a la población en cuanto a su volumen, estructura, dinámica y distribución en el territorio nacional, con el fin de lograr que participe justa y equitativamente de los beneficios del desarrollo económico y social". ${ }^{29}$ Regresando a los registros estadísticos, de acuerdo con datos oficiales, el número de extranjeros residentes en México para 1990 ascendería a 340.824, mientras que para 2000 llegaría a 492.298, y para 2010 a 967.803, en los que se manifestaría una progresiva diversificación de las nacionalidades presentes, dentro de las cuales Colombia empezaria a figurar (tabla 1).

Tras el cierre progresivo de fronteras en Estados Unidos a raíz de los sucesos de los atentados a las Torres Gemelas en 2001, se fortalecerian los diversos filtros migratorios implementados con las Illegal Immigration Reform and Immigrant Responsibility Act (IIRIRA) de 1996, y USA Patriot Act de 2003. A raíz de ello, las migraciones ilegales tendrían un mayor nivel de control y vigilancia, y el sistema de cuotas migratorias sería reducido bajo los parámetros rectores de la Homeland Security Act de 2002. Esto no solamente influyó en las poblaciones transmigrantes en México, sino también condicionaría los procesos migratorios de la diáspora colombiana.

A partir de ese panorama, y de otros factores internos como el deterioro del escenario político y económico tras la crisis económica de 1999 y del fracaso de los Diálogos del Caguán en 2002, "se diversificaron los destinos, lo que trajo como consecuencia la extensión de las migraciones hacia Europa, especialmente a España, así como a lugares no tradicionales en América Latina”. ${ }^{30}$ Estas tendencias

28 Alan Knight, "México, 1930-1946”, op. cit.

29 Ley General de Población, Diario Oficial de la Federación, Ciudad de México, México, 7 de enero de $1974,2015$.

30 María ECHEVERR, "Fracturas identitarias: migración e integración social de los jóvenes colombianos en España”, Migraciones internacionales 3 (2005), pp. 141-164. Citada por: Mauricio Palma, “¿País de emigración, inmigración, tránsito y retorno? La formación de un sistema de migración colombiano”, Revista del Observatorio de Análisis de los Sistemas Internacionales 21 (2015), p. 12. 
no solamente se desarrollaron hacia destinos tradicionales en la región como Venezuela y Ecuador, sino también contribuyeron a la aparición de nuevos destinos de presencia masiva, tales como Panamá, Canadá, Argentina, Chile, entre otros países que percibieron un crecimiento exponencial de población colombiana radicada en dichos lugares, entre ellos México.

Dichas condiciones, como elementos determinantes para la diáspora, "se han convertido en principios que contriñen las actividades y expectativas de migrantes prospectivos". ${ }^{31}$

\section{MÉXICO: UN NUEVO PUERTO PARA LA DIÁSPORA COLOMBIANA}

Las anteriores cifras han representado un crecimiento exponencial de la población en cuestión, sin precedentes en la historia migratoria mexicana, por lo cual es necesario comprender el estado y la naturaleza de las tendencias migratorias de la diáspora colombiana en México durante los últimos 25 años. Con base en lo anterior, es posible afirmar que el crecimiento de la diáspora colombiana en este país coincidió con el periodo de auge migratorio percibido desde los años ochenta. No obstante, es necesario aclarar que la principal razón de los colombianos para migrar no ha estado exclusivamente vinculada el conflicto armado, sino que, a la luz de la lectura de Mauricio Palma, en diálogo con la teoría de los sistemas de migración de Oliver Bakewell, en el fenómeno de la diáspora colombiana prevalece la existencia de "una multiplicidad de factores, tradiciones, estrategias y condiciones coyunturales que se consolidan como ejes que configuran el fenómeno migratorio y sus variaciones tendenciales". ${ }^{32}$ Elementos como las tradiciones migratorias de las primeras oleadas, los destinos, las experiencias y las formas de migración, entre otros elementos específicos, constituyen un capital humano que determina los patrones y las tendencias de adaptación social de los migrantes dentro de los países receptores. Para el caso de la diáspora colombiana, tomando los postulados teóricos anteriores, además de los embates del conflicto armado, los elementos configuradores de la cultura de migración se caracterizan por:

... diferentes flujos, instituciones y estrategias moldearon así, tanto numérica como conceptualmente, la tradición diaspórica colombiana en el extranjero. Esta se articula hoy con el lugar de origen a través de redes transnacionales conformadas por migrantes e instituciones de migración, que facilitan la difusión de información para los migrantes prospectivos, de cara al mercado laboral, las características de la sociedad receptora o los pormenores del alojamiento y estadía [...] También, se convierte en causa del origen y de la perpetuación del fenómeno en muchos casos. ${ }^{33}$ 
Ahora bien, la primera ola migratoria de colombianos que se trasladaron a este país fue a mediados de los años setenta, quienes migraron por el contexto del país, que experimentaba un cambio político con el fin del Frente Nacional en 1974; en este periodo se destacaría la promulgación del Estatuto de Seguridad de 1978 como medida para la constitución de un Estado de Excepción durante la presidencia de Julio César Turbay Ayala (1978-1982); la Ley de Amnistía de 1982 y los Acuerdos de La Uribe con las FARC en 1986, durante la presidencia de Belisario Betancur (1982-1986); el creciente auge del narcotráfico; la proliferación de acciones guerrilleras y paramilitares, ${ }^{34}$ entre otros elementos que condicionarian el entorno sociopolitico colombiano.

En el caso de México, bajo el contexto internacional de la época y su bipolaridad, la Guerra Fría marcó un hito en la migración y en sus principales países de destino. Su aparente neutralidad política, su economía superficialmente estable, y sus avances legislativos sobre asuntos migratorios con la Ley General de Población de 1947, convertian a México en un destino recurrente para todo aquel que tomara la decisión de emigrar o refugiarse. Respecto a este fenómeno,

... alrededor de un millón de sudamericanos, entre argentinos (650 mil), chilenos (200 mil) y uruguayos (200 mil) abandonaron sus respectivos países de origen durante la vigencia de las dictaduras militares. Pero la proporción de esta población llegada a México bajo la característica de asilado, al parecer, fue muy pequeña. Los anuarios Estadísticos, fuente oficial que consigna la calidad migratoria sin especificar el lugar de nacimiento o nacionalidad, registra para 1980 la cifra de 2404 extranjeros instalados en México como asilados. ${ }^{35}$

Teniendo en cuenta lo anterior, es posible afirmar que la tendencia migratoria de los colombianos en México no surgió por procesos de asilo y persecución política. Puesto que, según el Instituto Nacional de Estadística y Geografía de México (Inegi), la población de colombianos residentes en México para 1970 era de 1133, y para 1980 era de $2.778,{ }^{36}$ lo cual contradice en un primer plano la unicausalidad del refugio como explicación del fenómeno migratorio colombiano a este país. No obstante, pesar de que en los registros censales de 1990 al 2000 se evidenció solamente un aumento del $21 \%$ de las migraciones, en los últimos dos censos se pasó de 6018 colombianos en México para el 2000, a 12.832 para el $2010^{37}$ (tablas 1 y 2), lo cual representa un incremento del 131,3\% en un periodo de 10 años.

Dentro de la dispersión territorial de la población colombiana en México se resalta la gran tendencia a la migración hacia los principales centros urbanos, pues las mayores concentraciones se dan en el Distrito Federal (4.677 personas) y el Estado de México (2.191), además de una presencia más reducida en estados como Jalisco

34 Christopher Abel y Marcos Palacios, "Colombia, 1958-1990", en Leslie Bethell (ed.), Historia de América Latina. Tomo XVI, Los países andinos desde 1930, Barcelona, Crítica, 1991, p. 240.

35 Rebolledo Klogues, "Extranjeros, nacionalismo y política migratoria en el México independiente, 1821-2000”, op. cit., p. 377.

36 Inegr, Base de Datos de Censos de Población y Vivienda, op. cit.

37 InEgi, Censo de Población y Vivienda 2010, op. cit. 
(1.174), Nuevo León (774), Puebla (440) y Querétaro (436) ${ }^{38}$ (Mapa 1). Además, la lectura realizada sobre dicha dispersión territorial muestra que la tendencia a ubicarse en grandes centros urbanos obedece a unas lógicas determinadas que distan de otros procesos migratorios vigentes en el país. Por ejemplo, la ausencia de migrantes ubicados en zonas de frontera al sur y norte del país demuestra que las migraciones colombianas hacia México no obedecen a tendencias de transmigración, como puede ser dominante en algunas poblaciones de nacionalidad guatemalteca, salvadoreña y hondureña, entre otros casos mencionados anteriormente. También, esta tendencia insinúa una mayor probabilidad de señalar que la población colombiana tiende a ser regularizada, debido a los estrictos controles migratorios de los aeropuertos presentes en las principales ciudades del país.

Dichas tendencias de dispersión territorial concuerdan con los perfiles laborales del migrante, puesto que ha tendido a desarrollar actividades dedicadas a la prestación de servicios, condición que tiene amplios mercados en zonas urbanas. Por ejemplo, en el plano laboral, en 2010, el 57,8\% del total de colombianos en México se declaró económicamente activo, en actividades en las que se destacan la prestación de servicios comunales, sociales y personales (2921); el sector de comercio, restaurantes y hoteles (1.404); en industrias manufactureras (837); y en el sector de telecomunicaciones y de transportes (708) (tablas 2 y 3).

Por otra parte, en el plano educativo se estima la presencia de 1428 estudiantes colombianos en el país, de los cuales se calcula por rango etario la existencia de 571 estudiantes en niveles universitarios, de posgrado, maestria y doctorado (tabla 2). Así, la migración estudiantil de tercer nivel también explica la tendencia a escoger centros urbanos para establecerse.

Además de la proximidad cultural, de la ventaja de compartir un mismo idioma y de ser un destino relativamente próximo en el aspecto geográfico, México se consolida como un país atractivo en temas educativos por su oferta en educación superior, al nivel de otros países de la región que son abanderados en este tema como Brasil, Chile y Argentina. De acuerdo con Francisco López Segrera, ${ }^{39}$ México contaba para 2008 con un sistema de educación superior de 2’384.858 estudiantes, con el $60 \%$ de la matrícula total regional de educación superior en América Latina, posición compartida con Brasil y Argentina. Además, se cuenta con la existencia de universidades de gran renombre mundial como la Universidad Nacional Autónoma de México (UNAM), el Instituto Tecnológico y de Estudios Superiores de Monterrey (TEC), entre otras.

En cuanto a los flujos migratorios, la tendencia de crecimiento se puede percibir desde antes de 2010. Los flujos por motivos educativos también se vieron incrementados desde el 2012, estos pasaron de 3068 a 5871 en el 2015 (figura 1). Por su parte, los flujos migratorios hacia México con fines laborales fueron de 12.006

38 Ibid.

39 Francisco López Segrera, "Tendencias de la educación superior en el mundo y en América Latina y el Caribe”, Avaliação 13 (2) (2008). 
para el 2012 y de 19.542 para el 2015 (figura 1). Esto quiere decir, a simple vista, que no solo son los incentivos y las características expuestas anteriormente en los planos académicos y laborales que señalan un atractivo migratorio México, sino que también ha sido manifiesta la existencia de espacios de cooperación bilaterales que han permitido un avance progresivo para la liberalización de los flujos migratorios entre ambos países.

\section{Tabla 1. Población extranjera en México por discriminación de nacionalidad}

\begin{tabular}{|l|r|l|r|l|r|}
\hline \multicolumn{1}{|c|}{ Censo 1990 } & \multicolumn{1}{c|}{340.824} & \multicolumn{1}{c|}{ Censo 2000 } & \multicolumn{1}{c|}{ 487.546 } & \multicolumn{1}{c|}{ Censo 2010 } & \multicolumn{1}{c|}{967.803} \\
\hline Estados Unidos & 194.619 & Estados Unidos & 342.131 & Estados Unidos & 738.103 \\
\hline Guatemala & 46.005 & Guatemala & 23.529 & Guatemala & 35.322 \\
\hline España & 24.873 & España & 20.455 & España & 18.873 \\
\hline El Salvador & 5215 & Cuba & 6558 & Colombia & 12.832 \\
\hline Colombia & 4964 & Argentina & 6388 & Cuba & 12.108 \\
\hline Argentina & 4635 & Colombia & 6018 & Francia & 7163 \\
\hline Francia & 4195 & Canadá & 5644 & China & 6655 \\
\hline Alemania & 4055 & Francia & 5629 & Alemania & 6214 \\
\hline Canadá & 3011 & Alemania & 5529 & Corea del Sur & 3960 \\
\hline Italia & 3004 & El Salvador & 5287 & Japón & 3004 \\
\hline
\end{tabular}

Fuente: elaboración propia basada en la información del Instituto Nacional de Estadística y Geografía (INEGI), compilada por el Proyecto IMILA - Celade de la Cepal (2017).

Tabla 2. Población colombiana por sexos, estado civil, condición de actividad e inactividad

\begin{tabular}{|c|c|c|c|c|c|c|c|c|c|}
\hline & \multicolumn{3}{|c|}{1990} & \multicolumn{3}{|c|}{2000} & \multicolumn{3}{|c|}{2010} \\
\hline & \multicolumn{3}{|c|}{4964} & \multicolumn{3}{|c|}{6018} & \multicolumn{3}{|c|}{12.832} \\
\hline Grupos de sexos & \multicolumn{2}{|c|}{ Hombres } & Mujeres & \multicolumn{2}{|c|}{ Hombres } & Mujeres & \multicolumn{2}{|c|}{ Hombres } & Mujeres \\
\hline & \multicolumn{2}{|c|}{2608} & 2356 & \multicolumn{2}{|c|}{2755} & 3263 & \multicolumn{2}{|c|}{5271} & 7561 \\
\hline Estado Civil (+15) & Total & Hombres & Mujeres & Total & Hombres & Mujeres & Total & Hombres & Mujeres \\
\hline Solteros & 1566 & 930 & 639 & 1249 & 640 & 609 & 2188 & 986 & 1202 \\
\hline Casados y Unidos & 2628 & 1346 & 1282 & 3622 & 1656 & 1966 & 8421 & 3235 & 5186 \\
\hline Otros & 249 & 60 & 189 & 460 & 110 & 350 & 411 & 80 & 331 \\
\hline Condición de actividad & Total & Hombres & Mujeres & Total & Hombres & Mujeres & Total & Hombres & Mujeres \\
\hline Activos & 1794 & 1255 & 539 & 2973 & 1875 & 1098 & 7425 & 3770 & 3655 \\
\hline Inactivos & 2756 & 1129 & 1627 & 2493 & 2131 & 5254 & 4091 & 834 & 3257 \\
\hline Inactivos & Total & Hombres & Mujeres & Total & Hombres & Mujeres & Total & Hombres & Mujeres \\
\hline Estudiante & 68 & 42 & 26 & 733 & 357 & 376 & 1428 & 623 & 805 \\
\hline Ama de casa & 951 & 14 & 937 & 1019 & 10 & 1099 & 2282 & 30 & 2252 \\
\hline Jubilado o pensionado & 1461 & 869 & 592 & 64 & 38 & 26 & 171 & 106 & 65 \\
\hline Otros & 276 & 204 & 72 & 677 & 198 & 479 & 168 & 33 & 135 \\
\hline
\end{tabular}

Fuente: elaboración propia basada en la información del Instituto Nacional de Estadística y Geografia (INEGI), compilada por el Proyecto IMILA - Celade de la Cepal (2017). 
Tabla 3. Población colombiana en México económicamente activa mayor de 15 años por actividad laboral

\begin{tabular}{|c|c|c|c|c|c|c|c|c|c|}
\hline COLOMBIA & \multicolumn{3}{|c|}{1990} & \multicolumn{3}{|c|}{2000} & \multicolumn{3}{|c|}{2010} \\
\hline $\begin{array}{l}\text { Actividad laboral } \\
(+15)\end{array}$ & Total & Hombres & Mujeres & Total & Hombres & Mujeres & Total & Hombres & Mujeres \\
\hline $\begin{array}{l}\text { Agricultura, caza } \\
\text { y pesca }\end{array}$ & 17 & 13 & 4 & 30 & 24 & 6 & - & - & - \\
\hline Minas y canteras & 7 & 7 & - & 13 & 11 & 2 & 186 & 87 & 99 \\
\hline $\begin{array}{l}\text { Industrias } \\
\text { manufactureras }\end{array}$ & 299 & 240 & 59 & 377 & 278 & 99 & 837 & 641 & 196 \\
\hline $\begin{array}{l}\text { Electricidad, gas } \\
\text { y agua }\end{array}$ & 2 & 2 & - & 6 & 5 & 1 & 2 & 2 & - \\
\hline Construcción & 44 & 36 & 8 & 422 & 282 & 140 & 128 & 102 & 26 \\
\hline $\begin{array}{l}\text { Comercio, } \\
\text { restaurantes y } \\
\text { hoteles }\end{array}$ & 271 & 209 & 62 & 76 & 63 & 13 & 1404 & 705 & 699 \\
\hline $\begin{array}{l}\text { Transportes y } \\
\text { comunicaciones }\end{array}$ & 30 & 27 & 3 & 44 & 36 & 8 & 708 & 483 & 225 \\
\hline $\begin{array}{l}\text { Intermediario } \\
\text { financiero/ } \\
\text { Empresa / } \\
\text { Alquiler }\end{array}$ & 55 & 30 & 25 & 498 & 300 & 198 & 477 & 220 & 257 \\
\hline $\begin{array}{l}\text { Servicios } \\
\text { comunales, } \\
\text { sociales y } \\
\text { personales }\end{array}$ & 981 & 625 & 365 & 1.335 & 779 & 556 & 2921 & 1130 & 1791 \\
\hline Servicio doméstico & 70 & 54 & 16 & 138 & 81 & 57 & 446 & 300 & 146 \\
\hline
\end{tabular}

Fuente: elaboración propia basada en la información del Proyecto IMILA - Celade de la Cepal (2017).

Para los colombianos, el panorama migratorio se ha transformado positivamente gracias al acercamiento económico y diplomático de ambos países. ${ }^{40}$ Esta aproximación, de la cual se destaca la participación en la Alianza del Pacífico, no solo ayudó al fortalecimiento comercial y financiero de los cuatro países miembros, sino también creó y reforzó incentivos migratorios como es la exención de visado, y la libre circulación de personas con finalidades de tipo laboral y académico, lo cual ha sido de considerable importancia en las tendencias migratorias percibidas entre 2012 y 2017 (figura 1).

La eliminación de visas empezó a aplicar el 9 de noviembre del 2012 para Colombia, y cambió las dinámicas migratorias hacia México. Por ejemplo, para los colombianos, el proceso de regularización documental se ha modificado durante los últimos años como resultado de la progresiva integración con México. Antes de la supresión del visado, ambos países suscribieron un Tratado de Libre Comercio en 1995; un Convenio de Reconocimiento Mutuo de Certificados de Estudios, Titulos y Grados Académicos de Educación Superior en 2001; un Acuerdo de Cooperación Turística en 2002 y un Convenio de Intercambio Cultural y Educativo en 2008,

40 Alianza del Pacifico, Declaración de Lima del 28 de abril de 2015, 2015. 
lo cual demuestra una estructura de acuerdos, vinculos y obligaciones que también facilitó la supresión de filtros para un futuro intercambio fluido de personas.

Con el levantamiento de la restricción del visado para colombianos, la migración y permanencia de esta población en territorio mexicano dejó de basarse en figuras como la naturalización. Igualmente, gracias a los diversos procesos de integración regional y al conjunto de leyes migratorias, varios colombianos han llegado como inmigrantes a México con becas o algún tipo de canon económico (ahorros, ayuda de un familiar, entre otros) para desarrollar sus estudios superiores, lo cual ha incidido en la baja sensible del número de cartas de naturalizaciones.

Además, si tomamos en cuenta las tendencias del crecimiento poblacional de los colombianos en México durante los últimos dos registros censales, es posible evidenciar que, según datos de la Secretaría de Relaciones Exteriores de México, ${ }^{41} \mathrm{el}$ número total de Cartas de Naturalización expedidas entre 2005 y 2010 pasó de 5610 a 2150 , mientras que solamente los flujos de salida de colombianos hacia México por concepto laboral entre 2007 y 2010 pasaron de 9976 a 10.371. Ante la existencia de esta tendencia diametralmente opuesta, es posible dilucidar que la utilización de la figura de la naturalización como trámite documental para la residencia permanente es cada vez menos utilizada en general. Además, dentro de un plano de constante desarrollo de integración económica, la migración se presenta cada vez más como un elemento acorde con el ritmo de avance en el mundo, en detrimento del manejo tradicional estatal de la entrada y salida de personas.

Por último, y como evidencia de la creciente importancia del fenómeno migratorio colombiano en México, en 2015 se creó el Grupo de Trabajo sobre Asuntos Migratorios y Consulares como mecanismo bilateral para "la realización de acciones conjuntas que permitan fortalecer la asistencia mutua a sus poblaciones migrantes en condición de vulnerabilidad y establecer estrategias en materia de cooperación judicial para facilitar la asistencia a sus detenidos". ${ }^{42}$ Los diversos aportes que pueden derivar de un mecanismo bilateral pueden ser señal de la construcción de una estructura de procedimiento mancomunado que pueda dar mayores luces en temas de monitoreo, control, análisis y ejecución de estrategias que lleven a la profundización en el conocimiento de lógicas migratorias competentes.

Cabe aclarar que esta revisión estadística es un reflejo del último censo mexicano, y que la ausencia de datos actualizados es el principal problema a la hora de estudiar la migración entre países latinoamericanos de una forma veraz, actualizada y vigente. Sin embargo, según reportes de las Naciones Unidas, ${ }^{43}$ las estimaciones de la población colombiana en México para 2015 ascienden a 20.135, lo cual va acorde con los estudios de las tendencias de los flujos migratorios

41 Secretaría de Relaciones Exteriores de los Estados Unidos Mexicanos, Estadísticas de los Servicios del artículo 27 constitucional, 2017.

42 Embajada de la República de Colombia en México, Mecanismos bilaterales, 2018, en méxico.embajada.gov.co

43 Organización de las Naciones Unidas (ONU), Total International Migrant Stock Report, New York, ONU, 2017. 
presentados. Al analizar los puntos expuestos se puede concluir que los resultados del próximo censo y la tendencia que ha presentado la población colombiana en México podrían aumentar en igual proporción a la actual, o por lo menos en una inclinación proporcional.

Del mismo modo, las estimaciones obtenidas en los censos nacionales utilizados para medir el volumen y la evolución de la emigración dejan ver que el flujo de población de Colombia hacia el exterior ha crecido en forma sostenida desde el siglo XX, pero se incrementó de manera notable en el siglo XXI. ${ }^{44}$

Tal vez uno de los intereses de la aproximación del Gobierno colombiano a sus aliados Perú, Chile y México sea por beneficios para la cooperación internacional y de crecimiento económico del país, ya que los dos últimos son miembros de la OCDE y desde hace unos años Colombia manifestó su voluntad de ser parte de dicha organización, de la cual logró su adhesión en 2018. Al realizar una mejor integración comercial y ayudar a la cooperación a mejor sus alcances internacionales, Colombia ha constituido sus relaciones bilaterales con México como aliado primordial para su posicionamiento internacional. De este modo, las facilidades que se puedan presentar a futuro para el libre tránsito y la migración misma harían que el flujo migratorio colombiano aumentara al abrir un nuevo campo de participación binacional y regional.

Figura 1. Evolución de los flujos migratorios de salida de colombianos hacia México por concepto de residencia en el exterior, motivos de estudios y motivos laborales, 2007-2015

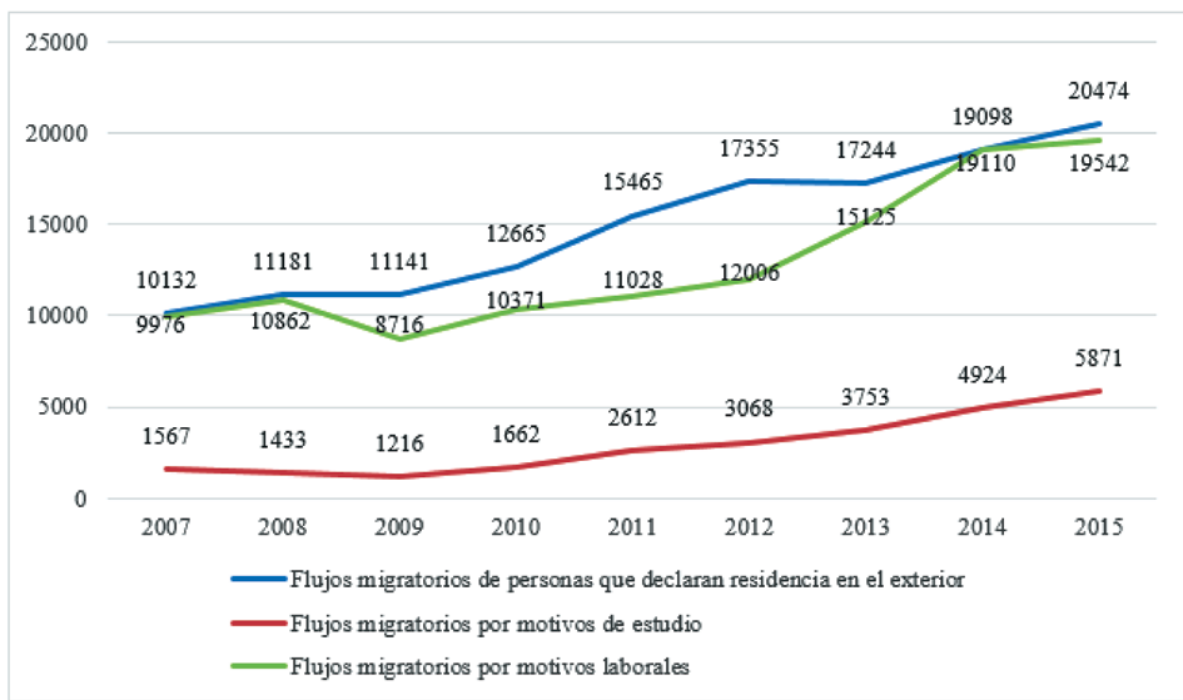

Fuente: elaboración propia basada en información provista por la Unidad Administrativa Especial Migración Colombia vía derecho de petición (2017).

44 William Mejía OchOA, "Colombia y las migraciones internacionales. Evolución reciente y panorama actual a partir de las cifras”, en Revista Internacional de Movilidad Humana 20 (2012). 


\section{REFLEXIONES SOBRE LA NATURALEZA DE LA DIÁSPORA COLOMBIANA EN MÉXICO}

Hasta el momento la migración se ha revisado tanto desde una perspectiva constructivista de la historia migratoria de México como desde una revisión estadística de tendencias demográficas de la migración colombiana. Es pertinente ahora profundizar sobre una posible lectura, desde un punto de vista reflexivo, sobre la naturaleza de esta migración. Como resultado de la exposición de cifras y resultados anteriormente plasmados, es evidente la pertinencia del modelo de expulsión-atracción, en el que se explican las migraciones "a partir de las decisiones racionales que toman los individuos en función de maximizar los beneficios y reducir los costos dadas las presiones en las que les ha tocado vivir". ${ }^{45}$ De acuerdo con lo anterior, y con los demás incentivos migratorios estudiados, México es un país de atracción gracias a sus características geográficas, históricas y culturales, y refuerza el planteamiento de las teorías de la migración enfocadas en los asuntos culturales, que lo llevan a posicionarse como un país que cada vez más profundiza su rol como receptor de migrantes.

Para los colombianos, gracias a los cambios en la supresión de requisitos de visado, en conjugación con los diversos contextos económicos, académicos y laborales, se mantuvo un crecimiento de forma paulatina y prolongada a lo largo de los años, demostrado en los últimos censos mexicanos. Sin embargo, llama la atención el hecho de que en el caso de las migraciones colombianas hacia México la tendencia sobre el diferencial salarial de la teoria neoclásica sea insuficiente para comprender la totalidad del tema -en Colombia, el salario mínimo asciende a 251 dólares mensuales, mientras que en México es de 136 dólares- ${ }^{46}$ así como el sostenimiento del crecimiento de migraciones no laborales de manera más acentuada, como las migraciones estudiantiles (tabla 2). Lo anterior puede deberse a que, como se mencionó, los factores de atracción han incrementado, entre ellos la facilidad de viajar a México sin visa y sin procesos consulares previos, al igual que los incentivos educativos al brindar becas a estudiantes para fortalecer el capital humano, lo que ha generado un mayor flujo de personas por turismo y negocios.

Aunque se partió de una lectura desde la mirada de la teoría de los sistemas de migración como elemento epistemológico para el estudio de la diáspora colombiana, sería de considerable valor hacer un ejercicio hermenéutico del tema en cuestión sin apelar a una lectura clásica sobre los incentivos migratorios, aunque su importancia sea fundamental para cualquier comprensión preliminar sobre este tema.

Acorde con los propósitos de las teorías del capital social, los cuales pretenden "responder a la cuestión fundamental del por qué unos individuos emigran a otros

45 David Roll et al., La diáspora latinoamericana a España, 1997-2007: incógnitas y realidades, Bogotá, Editorial Universidad del Rosario, 2012, p. 54.

46 Consultado en la página web http://www.salariominimo2017.de/mexico/ 
países y otros no lo hacen", ${ }^{47}$ una de las posibles perspectivas para entender la visión del migrante para la toma de su decisión de migrar puede determinarse por el "imaginario" del destino. La construcción de sensaciones de proximidad, cercanía cultural, similitud geográfica e, incluso, simpatía y admiración cultural, son elementos que pueden determinar la actitud de un migrante prospectivo.

Para el caso presente, y sin la pretensión de suponer una actitud generalizada de los migrantes colombianos sobre México como país y realidad cultural, para Fernando Dorado ${ }^{48}$ hay una cierta visión que prevalece en el colombiano sobre este país:

Antes de avanzar reitero mi convicción de que México es para todos nosotros una gran y admirada nación. Para los colombianos del común -para los "zarrapastrosos” del pueblo que andábamos a pie limpio hasta hace unos 50 años-, México era lo máximo. Desde sus revolucionarios de principios de siglo como Zapata y Villa, pasando por actrices, cantantes, cómicos, humoristas como el inolvidable "Cantinflas" o protagonistas de la "lucha libre" como el "Santo", "Máscara de Plata" o "Huracán” Ramírez, todos eran unos personajes increíbles para nosotros. México era lo máximo, era digno de imitar, un símbolo de dignidad popular y de autenticidad mestiza e india que nos hacía enorgullecer el alma latinoamericana. ¡Ay! ¡Méjico lindo y querido!

Teniendo en cuenta estas percepciones, es posible comprender que dicha visión haya contribuido a la concepción de México como un destino cercano a la realidad del colombiano; condición que puede ser un capital humano explotable para la adaptabilidad del posible migrante en su nuevo país. Además, dicha sensación de cercanía no solo se da por la vigencia de un imaginario cultural tangible en Colombia que mantiene un valor social considerable, sino también por condolencia o identificación por la experiencia compartida de problemáticas similares dentro de las realidades particulares de cada país.

Por ejemplo, Dorado ${ }^{49}$ retoma sus reflexiones sobre las similitudes entre México y Colombia respecto de flagelos como la violencia y el narcotráfico:

Pero... entonces, ¿qué nos pasó en el camino? ¿Cómo se perdieron esas cualidades y valores a lo largo del siglo XX? ¿Cómo fue que nos metimos en esta ola de violencia que aterra a nuestras gentes? Unos nos preguntamos porque ya lo vivimos en toda su intensidad por allá entre 1985 y 2005, y otros porque como en el país "manito", lo están sufriendo en toda su crudeza. En esos tiempos, "capos" de la naturaleza de Pablo Escobar y Gonzalo Rodriguez Gacha o comandantes paramilitares como los hermanos Castaño, cometían atentados, asesinatos, masacres tan

47 Natalia Ribas, "Inmigración para un nuevo siglo: problemas y oportunidades", en Revista Étnicas, Cuadernos Étnicas, 2000.

48 Fernando Dorado, "México y Colombia. Al rescate de la identidad popular", en Revista FAIA I (1) (2012).

49 Ibid. 
crueles como las que hoy vemos que se realizan en México a manos de los asesinos a sueldo de los carteles del Golfo, los Zetas y demás bandas criminales y paramilitares que se han organizado en esa nación.

Teniendo en cuenta lo anterior, es posible comprender esa expresión sobre la similitud entre ambos países frente al trauma de la violencia, y es viable señalar que hay una posible condición de reflejo de identidad ante un trauma psicosocial. De acuerdo con Marina Pereira Condinanza, ${ }^{50}$ un trauma psicosocial es "una situación traumática que afectó no solo a individuos aislados, sino a la comunidad en su conjunto". Dicha situación traumática es un elemento que incide directamente en el mantenimiento de una "relación dialéctica entre el individuo y la sociedad, refiriéndose a que en diversas ocasiones los sujetos vivencian experiencias extremas de carácter colectivo, pero deben enfrentar a las mismas desde sus propios recursos individuales". Es alli donde, ante la presencia de hechos traumáticos como la violencia generalizada por el narcotráfico, de una u otra forma es posible incidir en una visión condescendiente, comprensiva e, incluso, de acercamiento, cooperación y entendimiento del colombiano con México y su realidad.

A partir de lo anterior, y según la concepción misma de México como parte del imaginario del colombiano, no solo estos elementos pueden construir instituciones que constituyen prácticas discursivas que configuran una cultura de la migración determinada, ${ }^{51}$ sino que también hacen parte de un entramado de perspectivas que nutre al capital social de las comunidades migrantes. Según Palma: ${ }^{52}$

La diversificación de la emigración por educación, por nexos afectivos o políticos, por la afinidad con el lugar de destino, la emigración por el descontento con el orden cultural en origen, por la expectativa de adquirir una experiencia migratoria, entre muchos otros factores, adquiere entonces relevancia en este sistema. Esto afecta el nivel del entendimiento cultural, que a su vez influye en el diseño de las instituciones y estrategias de las que habla Bakewell, pero sobre todo en las dinámicas que gobiernan la migración.

Por ende, es posible relacionar que dentro del sistema de migración colombiano, a pesar de que existen diversos elementos que determinan la existencia de dicho entramado para la migración, es plausible determinar que las experiencias migratorias no obedecen plenamente a instintos y mecanismos de decisión exclusivamente racionales. Aunque los incentivos tangibles puedan ser determinantes y persuasivos para quien tome la decisión de migrar, también es correcto concebir que esta decisión está transversalmente influida por elementos profundamente personales como las proximidades culturales, la empatía con el destino o, incluso, la experiencia sobre una visión similar de una experiencia colectiva traumática.

50 Mariana PEREIRA CondinAnZa, Memoria, trauma e identidad: rupturas y reencuentros, trabajo de Grado, Universidad de la República de Uruguay, s. f.

51 Mauricio PALMA, “¿País de emigración, inmigración, tránsito y retorno? La formación de un sistema de migración colombiano”, en Revista del Observatorio de Análisis de los Sistemas Internacionales 21 (2015).

52 Ibid. 


\section{CONCLUSIONES}

Como resultado del ejercicio anterior de análisis de la naturaleza de la migración colombiana en México, es posible determinar que este caso de estudio se ha desarrollado paralelamente con un proceso de apertura migratoria sin precedentes en el país receptor. A pesar de que existen unas particularidades en el desarrollo de las gestiones migratorias para la atracción de extranjeros que residan en territorio mexicano, los flujos principales han estado directamente influenciados por elementos circunstanciales, tales como la herencia hispánica, la vecindad con Estados Unidos, los exilios políticos en América Latina y el hecho de ser un país de paso en procesos transmigratorios provenientes de América Central.

En el caso de la diáspora colombiana, a pesar del ambiente político y social de las migraciones en México como resultado de las dinámicas de la Guerra Fría, ambiente marcado por el cambio administrativo en las iniciativas de recepción posteriores a la Revolución mexicana, la existencia de un crecimiento sostenido representaba una condición particular para el fortalecimiento de un flujo migratorio considerable.

Reflexionando sobre el comportamiento de la migración colombiana en México se podría concluir que el panorama migratorio se ha transformado positivamente. No solo por la eliminación de restricciones de visado para el libre flujo de personas y el progresivo acercamiento diplomático entre ambos países, sino también por ser un proceso migratorio que ha tendido al alza durante los últimos 30 años.

No solamente por los sólidos incentivos que determinan la elección de México como destino migratorio, tales como el progresivo crecimiento económico, la oferta académica, la cercanía cultural, entre otros elementos que pueden ser rectores, sino también por ser parte de un nuevo ciclo de expansión de la diáspora colombiana, tanto en destinos como en número de personas. A pesar de que México no se constituyó como un país receptor de poblaciones masivas de migrantes durante la mayoria de su vida independiente, actualmente juega un rol de gran importancia en las lógicas migratorias latinoamericanas. Además de su proverbial diáspora en el exterior, de la cual destaca su población en Estados Unidos, México ha comenzado a ser un actor protagónico en los procesos migratorios dentro de América Latina.

Aunque existan algunos actores que mencionen que México se ha "alejado del mundo" con sus politicas de cierre a las migraciones, las mismas circunstancias de los últimos años lo han vinculado en nuevos procesos migratorios. Para finalizar, al realizar el ejercicio de comprender la naturaleza de la diáspora colombiana en México, es inevitable comprender la evolución histórica de un país en el que, ante los diversos embates de la historia, la migración ha sido un tema de trascendencia nacional para su renovación. 


\section{BIBLIOGRAFÍA}

Abel, Christopher y Marcos Palacios, "Colombia, 1958-1990", en Leslie Bethell (ed.). Historia de América Latina. Tomo XVI, Los países andinos desde 1930, Barcelona, Crítica, 1991, pp. 209-258.

Alianza del Pacifico, Declaración de Lima del 28 de abril de 2015. 2015, en http:// www.sice.oas.org/TPD/Pacific_Alliance/Presidential_Declarations/I_Summit_Lima_Declaration_s.pdf, fecha de consulta: 16 de septiembre de 2017.

Bazant, Jan, "México", en Bethell, Leslie (ed.), Historia de América Latina. Tomo VI, América Latina Independiente, 1820-1870, Barcelona, Crítica, 1991.

Chiarello, Leonir. "Las politicas públicas sobre migraciones y la sociedad civil de América Latina”, en Scalabrini International Migration Network, (2011), pp. 447-580, en http://www.dedihc.pr.gov.br/arquivos/File/LasPoliticasPublicasSobreMigraciones.pdf, fecha de consulta: 2 de noviembre de 2017.

Comisión Económica para América latina y el Caribe (Cepal), Investigación de la migración internacional en Latinoamérica [Bases de datos de censos para países latinoamericanos y del Caribe]. 2017, en https://celade.cepal.org/bdcelade/ imila/, fecha de consulta: 12 de octubre de 2017.

Comisión Económica Para América latina y el Caribe (Cepal), Red de datos para áreas pequeñas por microcomputador - REDATAM [Bases de datos de censos para países latinoamericanos y del Caribe]. 2017, en https://www.redatam.org/redbin/ RpWebEngine.exe/Portal?lang=esp, fecha de consulta: 12 de octubre de 2017.

Constitución Política Colombiana, Asamblea Nacional Constituyente, Bogotá, Colombia, 6 de julio de 1991.

Constitución Política de los Estados Unidos Mexicanos, Congreso Constituyente de México, Querétaro, México, 5 de febrero de 1917.

Cosio Villegas, Daniel et al. Historia Minima de México, México D. F., El Colegio de México, 1974.

DoRADo, Fernando, "México y Colombia. Al rescate de la identidad popular", en Revista FAIA I (1) (2012). En https://www.alainet.org/images/Mexico\%20y\%20 Colombia,\%20Al\%20rescate\%20de\%20identidad\%20popular.pdf

EcheverRI, María, "Fracturas identitarias: migración e integración social de los jóvenes colombianos en España", Migraciones Internacionales, 3 (2005), pp. 141-164, en http://www.scielo.org.mx/scielo.php?script=sci_ abstract\&pid=S1665-89062005000100006\&lng=en\&nrm=iso, fecha de consulta: 2 de noviembre de 2017.

Elzondo Mayer-Serra, Carlos, "Tres trampas: sobre los origenes de la crisis económica mexicana de 1994", en Revista de Economía Política 18 (1997), pp. 122-140, en http://www.rep.org.br/PDF/72-8.PDF, fecha de consulta: 2 de noviembre de 2017. 
Embajada de la República de Colombia en México, Mecanismos bilaterales, 2018, en http://mexico.embajada.gov.co/colombia/mecanismos_bilaterales

HaRris, John y Michael Todaro, "Migration, unemployment and development: A two-sector analysis”, en The American Economic Review 60 (1970), pp. 126142, en https://www.jstor.org/stable/1807860, fecha de consulta: 2 de noviembre de 2017.

Instituto Nacional de Estadística y Geografía (Inegi), Base de datos de censos de población y vivienda, Ciudad de México, Instituto Nacional de Estadística y Geografia, 2018.

Instituto Nacional de Migración (INM), Programa Especial de Migración (PEM) 20142018, Ciudad de México, Instituto Nacional de Migración, 2015.

KATz, Friedrich, "México: la restauración de la República y el Porfiriato, 1867-1910", en Leslie Bethell (ed.), Historia de América Latina. Tomo IX, México, América Central y el Caribe, 1870-1930, Barcelona, Crítica, 1991, pp. 13-77.

Knight, Alan, "México, 1930-1946”, en Leslie Bethell (ed.), Historia de América Latina. Tomo XIII, México y el Caribe desde 1930, Barcelona, Crítica, 1991, pp. 13-83.

Ley General de Población, Diario Oficial de la Federación, Ciudad de México, México, 7 de enero de 1974, 2015, en http://www.diputados.gob.mx/LeyesBiblio/ pdf/140_011215.pdf, fecha de consulta: 16 de septiembre de 2017.

Ley de Migración, Diario Oficial de la Federación, Ciudad de México, México, 25 de mayo de 2011.

Ley de Nacionalidad, Diario Oficial de la Federación, Ciudad de México, México, 23 de enero de 1998.

Lothar Weis, Thomas y Pedro López Chaltel, México: políticas públicas beneficiando a los inmigrantes. Ciudad de México, OIM, 2011, en https://publications. iom.int/books/mexico-politicas-publicas-beneficiando-los-migrantes, fecha de consulta: 2 de noviembre de 2017.

Mejí OchoA, William, "Colombia y las migraciones internacionales. Evolución reciente y panorama actual a partir de las cifras", en Revista Internacional de Movilidad Humana 20 (2012), pp. 185-210, en http://www.scielo.br/pdf/remhu/v20n39/v20n39a10, fecha de consulta: 12 de octubre de 2017.

Ministerio de Comercio, Industria y Turismo de Colombia, Con visita de presidente electo de México a Colombia se reafirma impulso de Alianza Pacífico, 2012.

ORGanización de Las Naciones Unidas (Onu), Total International Migrant Stock Report, 2017, en http://www.un.org/en/development/desa/population/migration/ data/estimates2/estimates15.shtml, fecha de consulta: 12 de octubre de 2017.

Palma, Mauricio, “¿País de emigración, inmigración, tránsito y retorno? La for114 mación de un sistema de migración colombiano”, en Revista del Observatorio de Análisis de los Sistemas Internacionales 21 (2015), pp. 7-28, en DOI: 10.18601/16577558.n21.02, fecha de consulta: 2 de noviembre de 2017. 
Pereira Condinanza, Mariana, Memoria, trauma e identidad: rupturas y reencuentros, trabajo de grado, Universidad de la República de Uruguay, s. f.

Rebolledo Klogues, Octavio, Extranjeros, nacionalismo y politica migratoria en el México independiente, 1821-2000, tesis doctoral. Repositorio Universidad de Granada, 2016.

RIBAS, Natalia, “Inmigración para un nuevo siglo: problemas y oportunidades”, en Revista Étnicas, Cuadernos Étnicas, 2000.

Roll, David et al. La diáspora latinoamericana a España, 1997-2007: incógnitas y realidades, Bogotá, Editorial Universidad del Rosario, 2012.

Secretaría de Relaciones Exteriores de los Estados Unidos Mexicanos, Estadísticas de los Servicios del artículo 27 constitucional, 2017, en http://sre.gob.mx/ estadisticas-de-los-servicios, fecha de consulta: 16 de septiembre de 2017.

Secretaría de Turismo de los Estados Unidos Mexicanos, Visitantes por Nacionalidad, 2017, en http://www.datatur.sectur.gob.mx/SitePages/Visitantes\%20por\%20 Nacionalidad.aspx, fecha de consulta: 16 de septiembre de 2017.

Smith, Peter H., “México, 1946-1990”, en Leslie Bethell (ed.), Historia de América Latina. Tomo XIII, México y el Caribe desde 1930, Barcelona, Crítica, 1991, pp. 84-150.

Unidad Administrativa Especial Migración Colombia. Respuesta a Derecho de Petición - 20172150262261. Información de acceso público mediante solicitud formal (19 de marzo de 2017).

VANEGas, Leonardo y Laura Vázguez Maggio, "Cambio estructural y migración: el caso de México”, Economía UNAM 39 (2016), pp. 3-25, en http://www.revistas.unam.mx/index.php/ecu/article/view/57074, fecha de consulta: 2 de noviembre de 2017.

Weber, David, The Mexican frontier, 1821-1846: the American Southwest under Mexico, Santa Fe, University of New Mexico Press.

Womack JR., John, “La Revolución Mexicana, 1910-1920”, en Leslie Bethell (ed.). Historia de América Latina. Tomo IX, México, América Central y el Caribe, 18701930, Barcelona, Crítica, 1991, pp. 78-145.

Yankelevich, Pablo, Inmigración y racismo. Contribuciones a la historia de los extranjeros en México, México: El Colegio de México, 2015. 


\section{ANEXO}

Figura 2. Mapa de dispersión territorial de los colombianos residentes en México, 2010

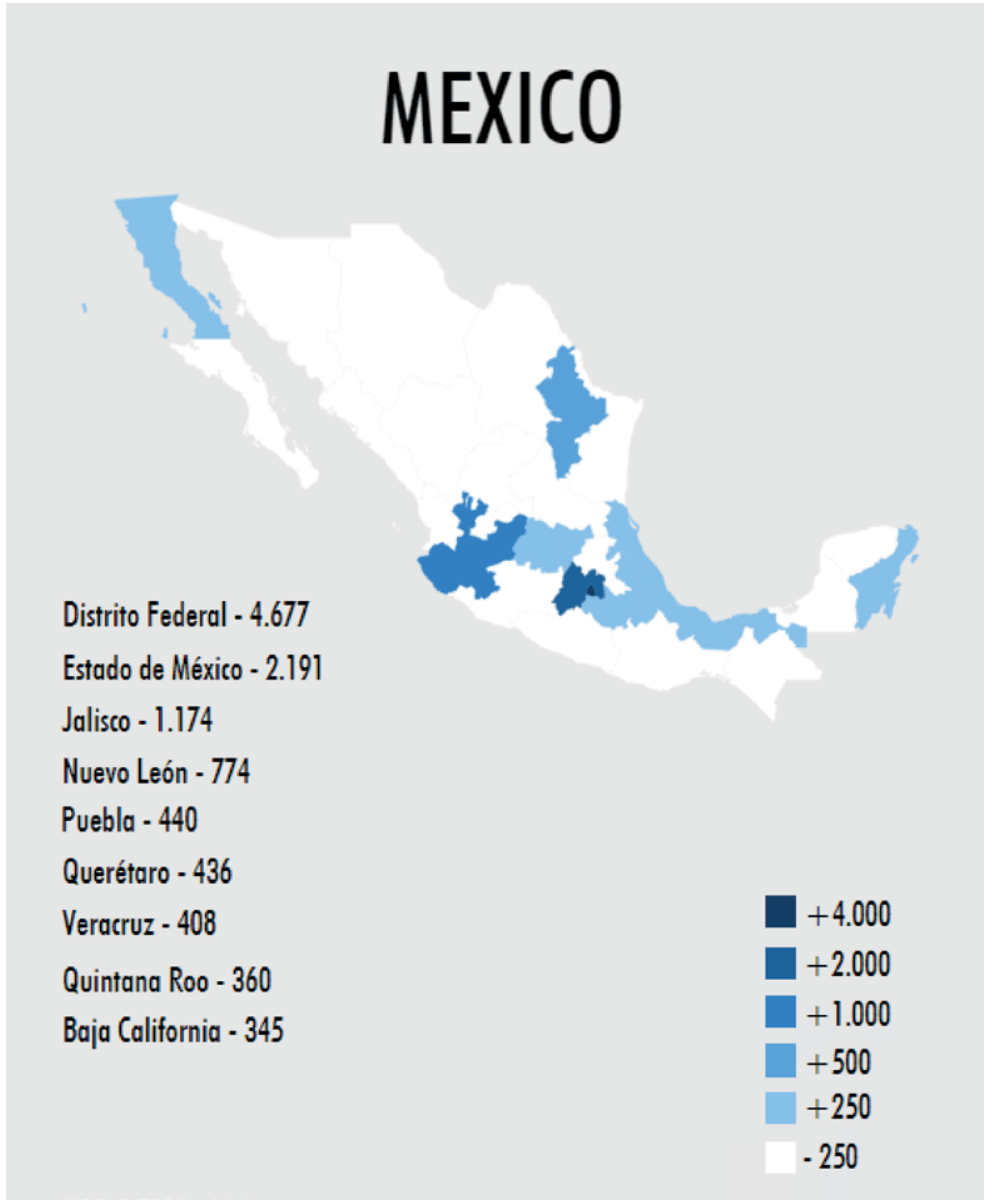

Fuente: elaboración propia basada en información del sistema REDATAM de la CEPAL (2017). 